\title{
The interannual stability of cumulative frequency distributions for convective system size and intensity
}

\author{
Karen I. Mohr \\ John Molinari \\ Chris D. Thorncroft \\ Department of Earth and Atmospheric Sciences \\ University at Albany, SUNY \\ Albany, NY 12222
}

Submitted to Journal of Climate, November 2008, revised April 2009

Corresponding author and new affiliation

Karen I. Mohr

Laboratory for Atmospheres

Code 613.1

NASA-Goddard Space Flight Center

Greenbelt, MD 20771

Voice: (301) 614-6360

Fax: (301) 614-5492

karen.mohr-1@nasa.gov 


\begin{abstract}
The characteristics of convective system populations in West Africa and the western Pacific tropical cyclone basin were analyzed to investigate whether interannual variability in convective activity in tropical continental and oceanic environments is driven by variations in the number of events during the wet season or by favoring large and/or intense convective systems. Convective systems were defined from TRMM data as a cluster of pixels with an $85 \mathrm{GHz}$ polarization-corrected brightness temperature below $255 \mathrm{~K}$ and with an area at least $64 \mathrm{~km}^{2}$. The study database consisted of convective systems in West Africa from May-Sep for 1998-2007 and in the western Pacific from May-Nov 1998-2007. Annual cumulative frequency distributions for system minimum brightness temperature and system area were constructed for both regions. For both regions, there were no statistically significant differences among the annual curves for system minimum brightness temperature. There were two groups of system area curves, split by the TRMM altitude boost in 2001. Within each set, there was no statistically significant interannual variability. Sub-setting the database revealed some sensitivity in distribution shape to the size of the sampling area, length of sample period, and climate zone. From a regional perspective, the stability of the cumulative frequency distributions implied that the probability that a convective system would attain a particular size or intensity does not change interannually. Variability in the number of convective events appeared to be more important in determining whether a year is wetter or drier than normal.
\end{abstract}




\section{Introduction}

In tropical continental regions with wet and dry seasons, an important scientific and economic objective is a better understanding of the mechanisms responsible for above normal and below normal wet seasons. The review paper on Sahelian climate by Nicholson (2000) identified one of the outstanding questions in this area of research: Are above normal years characterized by more precipitation events or by a tendency of precipitation events to be larger and/or more intense? Conflicting observations from recent papers on this topic add urgency to investigating this open question.

In this paper, we show results from the very different environments of West Africa (Figure 1) and the western Pacific Ocean (Figure 2) to test the hypothesis that interannual variability in convective system activity in tropical continental and oceanic environments is driven by variations in the number of events during the wet season and not by favoring large and/or intense events. Because this study considers two very large regions, we use $85 \mathrm{GHz}$ orbital resolution data from the Tropical Rainfall Measuring Mission (TRMM) satellite to analyze convective system number, size, and intensity. Although studies based on microwave remote sensing are not directly measuring precipitation on the ground, the use of the $85 \mathrm{GHz}$ brightness temperature is a well established proxy for the intensity of convective updrafts and thus the potential for precipitation on the ground (e.g., Mohr and Zipser 1996; Nesbitt et al. 2000; Toracinta et al. 2002; Cecil et al. 2005).

Nicholson (2000) summarizes papers on the daily precipitation climatology (1950-90) of a study site in Niger by Le Barbe' and Lebel (1997) and precipitation monitoring at the site (1990-93) by Lebel et al. (1997) then compares them with Nicholson et al. (1988) and Lamb et al. (1998). In Le Barbe' and Lebel (1997), almost $90 \%$ of the annual rainfall decrease over their 
study period was explained by the decrease of the mean number of precipitation events during July and August, while both the length of the wet season and the mean event precipitation remained stable. Using a dense network of recording gauges, Lebel et al. (1997) observed the same phenomena. In contrast, Lamb et al. (1998) conclude that the interannual variability 1951-87 at four different locations (Dakar, Bamako, Kindi, Niamey) was strongly correlated with a decrease in the number of strong disturbance lines but an increase in the number of weak disturbance lines. For the Sahelian rain gauges surveyed by Nicholson et al. (1988), the total number of precipitation days is described as "somewhat higher" in the wet years, but the increase is almost exclusively in the number of days with $40 \mathrm{~mm}$ or more. Nicholson et al. (1988) attribute the difference between wet and dry Augusts at their stations to as little as one or two major systems bringing between 100 and $150 \mathrm{~mm} \mathrm{~d}^{-1}$.

Papers after 2000 include a follow-up study by Le Barbe' et al. (2002) of the time period 1950-90 for a larger area of West Africa. Their analysis of daily precipitation data from 300 gauges revealed a systematic decrease since 1970 in the number of precipitation events. Decreases in interannual precipitation in the Guinea Coast and the Sahel were most closely correlated to decreases in precipitation events during the core of their wet seasons, May and June and July and August, respectively. However, the variations of mean precipitation per event were erratically distributed and uncorrelated to the mean interannual precipitation. Updating and extending the study by Lamb et al. (1998), Bell and Lamb (2006) attribute the decrease in rainfall 1970-90 to a decrease in the number of strong disturbance lines and an increase in weak disturbance lines. They found more variability in the numbers of weak vs. strong disturbance lines after 1990. For a Niger study area similar to Bell and Lamb's, Balme et al. (2006) observed no interannual variability in cumulative frequency distributions (CFD) of precipitation intensity 
$\left(\mathrm{mm} \mathrm{h}^{-1}\right)$ derived from recording rain gauge data for 1990-2002. Over a wide swath of subSaharan Africa, Mohr (2004) identified and analyzed convective systems from TRMM data for 1998-2001 but did not find significant interannual variability among the CFDs for the size of the precipitating area nor among the CFDs for convective intensity. Reconciling our results with differing conclusions from these previous studies is an important task of the present study.

Figure 2 defines the WPTCB and three sub-regions used in our study. There were cold phases (La Niña) in 1998 and 1999 and a warm phase (E1 Niño) in 2002. In Figure 2, the shifts in genesis density among the sub-regions broadly confirm Chan's (1985) observation that the anomalous Walker circulations associated with warm and cold phases of the El Niño-Southern Oscillation (ENSO) shift areas of enhanced and suppressed tropical cyclone activity. Although interannual variability rather than ENSO is the focus of Chen et al. (1998), the influence of ENSO on tropical cyclone formation can be inferred from their results. Wang and Chan (2002) demonstrate that the total number of tropical storms formed in the entire WPTCB does not vary significantly from year to year, but during El Niño summer and fall, the frequency increases in the southeast quadrant $(0-17 \mathrm{~N}, 140 \mathrm{E}-180)$ and decreases in the northwest quadrant $(17-30 \mathrm{~N}$, $120-140 \mathrm{E})$.

Tropical cyclones are but one part of the total spectrum of precipitation events that may occur in the tropical oceans. Since smaller precipitating systems may be the seedlings of tropical cyclones, analyzing the characteristics of oceanic precipitation and precipitating systems is relevant to assessing probability of tropical cyclone formation. In Mapes and Houze (1993) analysis of IR cloud clusters during several ENSO events in the 1980s, there are noticeable differences in the cumulative fraction of cold $(<235 \mathrm{~K})$ cloud between warm and cold events, implying a reduction in cold cloud events of all sizes in the WPTCB during warm events. Using 
$85 \mathrm{GHz}$ data from the Special Sensor Microwave/Imager (SSM/I), Zolman et al. (2000) created a census of the numbers and properties (size, intensity) of mesoscale convective systems (MCS) occurring in 18 sub-regions between $35 \mathrm{~N}$ and 35S during the 1995-96 La Niña. They compared their results to a similar census of MCSs during the 1993 El Niño compiled by Mohr and Zipser (1996). The areas with direct ties to ENSO - central Pacific, eastern Pacific, and Maritime Continent-demonstrated the largest differences in the number of MCSs between the 1995-96 La Niña and the 1993 El Niño. The properties of the MCSs (median and $90^{\text {th }}$ percentiles for size, median and $10^{\text {th }}$ percentiles for minimum $85 \mathrm{GHz}$ brightness temperature) did not change significantly. In Berg et al. (2002), differences in the mean vertical structure of eastern vs. western Pacific convective systems were pronounced in Dec-Feb 1999-2000, a period lacking a significant ENSO signal. During a warm event in Dec-Feb 1997-98, the increase in tall and large cloud systems in the eastern Pacific and the decrease in the western Pacific resulted in similar mean vertical structures, although regional differences such as a larger fraction of stratiform rain in the eastern Pacific remained.

We consider whether in some years large and/or intense convective systems constitute a larger share of the convective system population. Although this is not a new question, the new contributions of this study include the analysis of a longer time period than previous studies using microwave remote sensing such as Mohr (2004), a larger area than papers using rain gauge data, and the contrasting of results in two very different environments.

\section{Data and Methods}

From November 1997 to late August 2001, the TRMM satellite flew at an altitude of approximately $350 \mathrm{~km}$. The satellite was raised to an altitude of approximately $402 \mathrm{~km}$ to extend 
its operational lifetime. For our analysis of convective systems, we used the TRMM Microwave Imager (TMI) ungridded brightness temperature data product 1B11. Prior to the 2001 boost, the resolution of the $1 \mathrm{~B} 11$ product at $85 \mathrm{GHz}$ is $4.4 \mathrm{~km}$ with a swath width of $760 \mathrm{~km}$. After the boost, the resolution degraded slightly to $5.1 \mathrm{~km}$ with a swath width of $878 \mathrm{~km}$. Although the 1B11 product has all the channels of the TMI, we chose the $85 \mathrm{GHz}$ channels for our analysis. The minimum $85 \mathrm{GHz}$ polarization-corrected brightness temperature (PCT) is derived from a simple linear equation combining the horizontally and vertically polarized $85 \mathrm{GHz}$ channels (Spencer et al. 1989). The use of this polarization-corrected brightness temperature mostly eliminates identification errors due to emissivity discontinuities resulting from reflective surface types (e.g., water, desert sand, ice), making it possible to distinguish precipitating cloud from a non-raining background. Minimum PCT is a useful proxy for system intensity because it is related to the production by convective updrafts of large ice hydrometeors (graupel and hail) that scatter high frequency microwave radiation from a satellite's field of view (Spencer et al. 1989; McGaughey et al. 1996).

The methodology used to identify convective systems from the $1 \mathrm{~B} 11$ product is described in Mohr (2004). Since a convective system implies a cluster of convective cells rather than individual cumulonimbus, we imposed a stricter criterion than Mohr (2004): a convective system is at least $64 \mathrm{~km}^{2}$, implying at least 4 contiguous $85 \mathrm{GHz}$ pixels with a PCT below $255 \mathrm{~K}$. Although there are precipitating events in oceanic environments that do not have ice scattering, by defining convective systems using $85 \mathrm{GHz}$ brightness temperatures below $255 \mathrm{~K}$, we insured that deep, glaciated convective cells were part of each of our oceanic events. A convective/stratiform discrimination algorithm developed by Prabhakara et al. (2000) was applied to each convective system to determine the area of the stratiform cloud and the locations, 
area, and approximate lifecycle stage of each convective cell (developing, mature, or decaying). The algorithm used the magnitude of horizontal PCT gradients to make these first-order distinctions. The information in the study database included the date, overpass time, location, minimum PCT, and size (total and areas of stratiform and developing, mature, and decaying convective cloud). Because convective systems were identified from contiguous pixels below $255 \mathrm{~K}$ and the altitude boost in $2001 \mathrm{did}$ not change the number of pixels/swath in the $1 \mathrm{~B} 11$ product and did not bias the number of convective systems identified per year. The boost increased beam filling and increased the distance between pixel centroids, from which we calculated system areas. We note where these changes affect our analysis of system size and intensity.

To avoid biases due to sampling, Negri et al. (2002) determined that an acceptable estimate from TRMM data of the diurnal cycle of precipitation over a $5^{\circ} \times 5^{\circ}$ box required a minimum of 4-h averaging over a wet season. For our West African database, we recorded convective systems from 1 May to 30 September for each year 1998-2007. May to September captures the height of the wet season in the Guinea Coast and later in the Sahel. To avoid sampling biases identified in Negri et al. (2002), all temporal averaging or counting schemes used at least 5 days of data. Testing our hypothesis in the highly variable West African environment required the analysis of a range of wet and dry years. The Joint Institute for the Study of the Atmosphere and Ocean at the University of Washington (http://jisao.washington.edu/) maintains precipitation anomaly indices for the Sahel and the Guinea Coast. We ascertained wet and dry years from their time series graphs, although some years are missing from the Gulf of Guinea time series. In those cases, we referred to the Bulletin of the American Meteorological Society annual climate assessments for more information. Some 
years (e.g., 2006) were drier than normal in the Sahel but not in the Guinea Coast, making it difficult to assign a category on a regional level. The full 10 years of TRMM data captured the range of conditions, wet, dry and normal, that the analysis required.

For our WPTCB database, we recorded convective systems during the most active months for tropical cyclones, 1 May to 30 November, for 1998-2007. Table 1 lists the annual convective system densities for West Africa and the WPTCB. Interannual contrasts in convective system density (Table 1) and tropical cyclone formation in the WPTCB (Figure 2) peaked during anomalies in the Southern Oscillation Index (SOI). In the WPTCB analysis, these SOI anomalies included two tropical cyclone seasons with a La Niña $(1998,1999)$ and a season with an El Niño (2002). There were also two seasons with an SOI as close to neutral as possible $(2000,2005)$. These seasons provided the greatest possible contrast between normal and anomalous SST conditions to test our working hypothesis.

From the seasonal databases, CFDs for system minimum PCT, system area, and system mean PCT for the mature cells were constructed. Because the ranking of size and intensity from microwave remote sensing and rain gauge data produces non-normal data distributions (typically lognormal), a non-parametric but still powerful hypothesis test is required. The non-parametric Mann-Whitney rank method, whose application was demonstrated in Mohr and Zipser (1996), was chosen for testing whether or not annual samples were drawn from the same or different populations. Significance level was set at $95 \%(\alpha=0.05)$.

A second TRMM product used in the analysis was the $3 \mathrm{~B} 43$ monthly $0.25^{\circ} \times 0.25^{\circ}$ merged sources precipitation estimate. The 3B43 algorithm combines the TRMM instrument retrieval (multiple channels), IR geostationary retrievals, and the monthly accumulated rain gauge analysis from the NOAA Climate Prediction Center. The final gridded product provides 
global high-resolution monthly precipitation totals between $50 \mathrm{~N}$ and 50S. Monthly accumulated precipitation was summed from May-Sep for West Africa and May-Nov for the WPTCB to obtain seasonal totals. We used this quasi-independent data source to examine how anomalies in size of convective system populations were linked to anomalies in precipitation.

\section{Statistics of Convective Systems in West Africa}

The CFDs in Figures 3 and 4 were derived from histograms of the entire database of convective systems for each respective year during the TRMM era in West Africa. Figure 3a contains the CFDs for total convective system size. Because of the five orders of magnitude difference between the largest and smallest convective systems, the abscissa has a logarithmic scale. There are two sets of curves in Figure 3a. The set of curves on top are the curves for 1998-2001 ("pre-boost"), and the set of curves on the bottom is for 2002-07 ("post-boost"). The gap between the sets of curves is not visually pronounced, although it is largest for the many small convective systems below $300 \mathrm{~km}^{2}$. Below $300 \mathrm{~km}^{2}$, the differences between pre- and post-boost curves are greater than 5\%. Differences between CFDs greater than $5 \%$ produced a statistically significant result in hypothesis testing, implying that the pre- and post-boost sets of curves were drawn from different populations. Within each set, the annual samples were drawn from the same population. The results from 2001 were affected by the boost in August such that it is slightly to the right of $1998-2000$ but not significantly so, implying that 2001 belongs to the pre-boost set of curves. Because large convective systems contribute the majority of seasonal precipitation (e.g., Mathon and Laurent 2001; Mohr 2004), the high-low chart in Figure 3b focuses on the upper bins of the CFDs in Figure 3a. The difference in the cumulative frequencies for large convective systems $2000-40000 \mathrm{~km}^{2}$ is less than $2 \%$. There is less 
variability in the CFDs even between pre- and post-boost years for large, well-organized convective systems than for small, less well-organized convective systems.

The CFDs for system minimum PCT are in Figure 4a. The curves were derived from convective systems in all stages of their lifecycles. Figure $4 \mathrm{~b}$, the CFDs for the mean PCT of mature cells, was composed from a sub-set of convective systems that had 4 or more cumulonimbus clouds identified as mature by the Prabhakara et al. (2000) algorithm. Neither Figure $4 \mathrm{a}$ nor Figure $4 \mathrm{~b}$ has statistically significant gaps among the curves. The separation among curves is less than 5\% for all bins. Mohr and Thorncroft (2006) classified intense convective systems in 1998 as having a system minimum PCT of less than $135 \mathrm{~K}$, the $10^{\text {th }}$ percentile for system minimum PCT in 1998, a near to slightly above average year for precipitation. In Figure $4 \mathrm{a}$, the median value of the $10^{\text {th }}$ percentile is $135 \mathrm{~K}$, making it a useful representative of the $10^{\text {th }}$ percentile for the classification of intense convective systems in any year of the TRMM era.

Documented intraseasonal modes of variability of precipitation during the West African wet season include the 15-20 day mode and the 40 day mode of the Madden-Julian Oscillation (Mounier and Janicot 2004; Mounier et al. 2007; Mounier et al. 2008). We made daily counts of convective systems for the study region and constructed a time series by calculating 5-day running means of the daily counts. The 5-day running means eliminated the effect of the diurnal cycle and easterly (i.e., synoptic timescale) waves. The selected wet seasons in Figure 5 include one with near-normal precipitation (1998), one drier than average (2001), and one wetter than average (2003). Each of these years displays the same 15-20 day mode of variability. The other years in the database (not shown) also display this mode of variability. The amplitudes of the 
oscillations vary between wet and dry years. Wetter years have higher crests and shallower troughs, whereas drier years have lower crests and deeper troughs.

Figure 6 contains the CFDs for minimum PCT for the individual wet and dry periods of 2001 and 2003. The seasonal mean is plotted for comparison. In both years, the wet and dry periods of May and June tend to cluster above the seasonal mean, and the wet and dry periods of July-September tend to cluster on and below the seasonal mean. Seasonally, the month group May-Jun corresponds to the peak of the wet season in the Guinea Coast and Jul-Sep to the wet season in the Sahel. Tests between wet and dry samples within the May-Jun group and within the Jul-Sep group revealed that they were drawn from the same population, although the spread is smaller $(<3 \%)$ in 2003 than in $2001(<5 \%)$. Tests between samples in the May-Jun group and samples in the Jul-Sep group did rise to the significant level, indicating that May-Jun samples (the height of the wet season on the Guinea Coast) and Jul-Sep samples (the wet season in the Sahel) are from different populations. Tests of samples across years within the same group (May-Jun 2001 vs. May-Jun 2003 and Jul-Sep 2001 vs. Jul-Sep 2003) were not statistically significant.

\section{Statistics of Convective Systems in the Western Pacific Tropical Cyclone Basin}

Climate assessments describe La Niña conditions beginning in the spring of 1998, becoming fully established by July, and persisting through 1999 into early 2000 (Bell et al. 1999; Adler et al. 2000; Bell et al. 2000; Lawrimore et al. 2001). Almost all of the 13 tropical cyclones plotted in Figure 2a originated in the west region during the 1998 La Niña. During the $1999 \mathrm{La}$ Niña, 20 tropical cyclones developed, 9 in the north region and 11 in the west region. Compared to 1998 , there were stronger La Niña conditions in 1999 throughout the entire tropical cyclone 
season. A transition to El Niño conditions took place in 2001, becoming fully established in spring of 2002 (Waple and Lawrimore 2003). During 2002, almost all of the tropical cyclones plotted in Figure 2c developed in the east region. From 2003-2006, the equatorial Pacific experienced near-neutral to El Niño conditions (Levinson and Waple 2004; Levinson 2005; Shein 2006; Arguez et al. 2007). The year 2005 began in a weak warm phase of ENSO that ended in March, followed by near-normal SSTs throughout the tropical cyclone season with deep convection and tropical cyclone activity (number, distribution) only slightly below average, although the number of typhoons was at the climatological mean (Shein 2006). A transition to La Niña conditions took place during mid-2007, becoming fully established in the fall (Levinson and Lawrimore 2008).

In Table 1, the east region has pronounced variability in convective system density due to ENSO. The CFDs for the east region for 1998-2007 are depicted in Figure 7. As in Figure 3a, there is a separation in Figure 7b due to the boosting of the TRMM satellite in 2001. Aside from the statistically significant difference between the pre-boost and post-boost set of curves, there are no other statistically significant differences in Figures $7 \mathrm{a}$ or $7 \mathrm{~b}$. The effect of the 2001 TRMM altitude boost is apparent in Figure 7c. In Jun-Sep 2000, there was a near-neutral SOI, and the east region had near-normal SSTs, making it possible to compare a near-neutral preboost year to neutral post-boost 2005 (Lawrimore et al. 2001). The differences between the area CFDs for convective systems less than $300 \mathrm{~km}^{2}$ are $6 \%-12 \%$, greater than the $5 \%$ threshold required to attain statistical significance. Above $300 \mathrm{~km}^{2}$, the differences between pre-boost and post-boost area CFDs decrease with increasing convective system area. The change in the viewing angle due to the altitude boost increased the distances between pixels in TMI imagery, most notably at the edges of the swath. Small convective systems at swath edge, composed 
solely of edge pixels, would exhibit the greatest impact of the altitude boost. Some of these small convective systems would be counted in higher bins in post-boost years than they would occupy if they were identified in pre-boost years. Both Figure $3 \mathrm{~b}$ and Figure $7 \mathrm{c}$ demonstrate the negligible effect of altitude boost on large convective systems. Beam filling due to the altitude boost also had a negligible effect on the minimum PCT CFDs. For 2005 vs. 2000, the differences in the minimum PCT CFDs were $-0.03 \%--0.75 \%$.

In Figure 8 are CFDs for system minimum PCT and system total area for the three subregions of the WPTCB, focusing on the La Niña (1998, 1999), El Niño (2002), and neutral (2005) years. We intended to make any ENSO-related differences more apparent by constructing Figure 8 without the other years in the TRMM database. However, no statistically significant differences emerge. The El Niño and neutral seasons (post-boost) have less than $2 \%$ separation between their area CFDs, as do the two La Niña seasons (pre-boost). The minimum PCT curves for the west and east regions (Figures 8a and 8c) have a less than 3\% separation. Separation among the curves for the north region (Figure 8e) is slightly higher but still less than $5 \%$.

Using the neutral season, 2005, as the basis for comparison to the seasons with ENSO events, Table 2 contains the percent change in the number of convective systems in each region vs. the number occurring in 2005. The values in Table 2 that are associated with the $1999 \mathrm{La}$ Niña and 2002 El Niño are typical of those phases of ENSO and consistent with previous studies assessing the large-scale dynamics of those years. For the 1998 La Niña, there are decreases in the west and north regions and a larger than expected decrease in the east region. Bell et al. (1999) list five primary precipitation anomalies related to the 1998 La Niña, of which two are relevant to this study: 1) increased rainfall across Indonesia, and a nearly complete disappearance 
of rainfall across the east-central equatorial Pacific; 2) above-normal rains across northwestern, eastern, and northern Australia. Although the positive precipitation anomalies in the east region disappeared during the transition to La Niña, the Walker circulation was not fully re-established until the fall of 1998. The positive precipitation anomalies associated with La Niña occurred after and thus south of the peak of both the wet and tropical cyclone seasons in the west region.

The analysis of the WPTCB had to account for effects of ENSO and the effects of the altitude boost. It is noteworthy that the pre-boost years were largely dominated by La Niña conditions and most of the post-boost period dominated by neutral to El Niño conditions. Because much of the 2000 study period was near-neutral, it was possible to separate those values affected by ENSO and those affected by the altitude boost of TRMM. The values in Table 1 and Table 2 are representative of the expected interannual and regional variability associated with the documented phases of ENSO from 1998-2007. The altitude boost affected the area and intensity CFDs, although this was statistically significant only for the left hand side of the area CFDs (convective systems $<300 \mathrm{~km}^{2}$ ).

\section{Synthesis of Results from Both Study Regions}

In Figures 3 and 4 for West Africa and Figures 7 and 8 for the WPTCB, the CFDs for size and intensity for both study regions display no statistically significant differences attributable to natural causes. The probability that a convective system will have a particular area or intensity appears to be stable interannually. In Tables 1 and 2, the number of convective systems with a particular area or intensity is not. The number of West African convective systems in wetter than average years $(1999,2003)$ is only about $10 \%$ greater than in average years $(1998,2005)$ and about $20 \%$ greater than in drier than average years $(2000-2002)$. In 
Figures 7 and 8, convective systems in the WPTCB have the same proportion of large and/or intense convective systems regardless of the value of the SOI. From Table 2, the number of convective systems in a WPTCB sub-region during warm SST anomalies can be expected to be $10 \%$ greater than in neutral conditions, and 10\%-20\% fewer during cold SST anomalies. In the Sahel, a $1 \%-2 \%$ reduction in the convective systems at the top of the curves in Figures 3 and 4 is a reduction on the order of the one or two major systems cited in Nicholson et al. (1988) as the difference between a wet year and a dry year.

Table 3 illustrates how subtle differences in the number of convective systems may result in larger differences in the amount of seasonal precipitation. The figures in Table 3 are derived from the 3B43 gridded monthly precipitation product. We chose 1999 and 2002 for comparison because 1999 is wetter than normal in West Africa and a La Niña year in the WPTCB, and 2002 is drier than normal in West Africa and an El Niño year in the WPTCB. The percent change in the number of convective systems recorded in Tables 1 and 2 is accompanied by a change in precipitation in Table 3 that is $5 \%-15 \%$ larger than the change in the number of convective systems. Tables 1-3 display statistics for entire regions. Precipitation in individual 3B43 gridcells varied as much as $50 \%$ from regional figures, with the variability in West Africa highest north of $10 \mathrm{~N}$, emphasizing the greater impact of anomalies on dry regions.

Bell and Lamb (2006) explain the conflicts between their conclusion and the work of Le Barbe', Lebel, and colleagues as due to differences in spatial scale and sampling. Bell and Lamb used all available daily rain gauges in $440 \mathrm{~km} \times 440 \mathrm{~km}$ catchments in Senegal, Niger, Mali, and Burkina Faso. Le Barbe' et al. (2002) used widely dispersed daily rain gauges from the Guinea Coast to the Sahel. Figure 9 depicts the effect of accumulating statistics from individual storms for two areas roughly the same size as Bell and Lamb but from two different climate zones. 
There is more variability in the CFDs in the Niger graph (Figure 9a). The dry years at the top of the cluster of curves, $2000,2001,2004$, are significantly different $(5 \%-10 \%)$ from the normal and wet years at the bottom, 1998, 1999, 2003. There are no statistically significant differences between CFDs for wet vs. dry years in the Ivory Coast/Ghana graph (Figure 9b). Because the more humid zone south of $10 \mathrm{~N}$ dominates the West African regional mean, different conclusions could arise from analysis of a regional-scale sampling area that incorporates humid climate zones vs. small sampling areas in the same semi-arid zone.

During an anomalously dry period, the probability that a large convective system will pass through a small sampling area is smaller than it would be during normal conditions. For a reduced regional population, a small study area in Niger is more likely to observe a proportionally larger reduction in the number of large convective systems than one in Ghana. For the anomalously dry decades $1970-90$, this is the effect that Bell and Lamb observed in their small sampling areas, magnified by normalizing their intensity indices by the standard deviation of mean daily precipitation for 1951-98. In Figures 6 and 9, the CFDs vary as much as $10 \%$, depending on sampling period, the size of the sampling area, and climate zone. In constructing Figure 7, we found that at least 4-5 days of convective system counts were required. Although $4^{\circ} \times 4^{\circ}$ may be insufficient in a semi-arid region, it appears to be adequate in a humid one.

In Tables 1 and 2, an anomalous SOI appears to affect the number of convective systems in the WPTCB, depending on the time of year and the pace and magnitude of the changes in the Walker circulation and SSTs associated with the value of the anomalous SOI. Convective system activity during the 1999 La Niña and 2002 El Niño increases moderately in the regions with warm SST anomalies and decreases in regions with cold SST anomalies. In Figures 7 and 
8 , the value of the SOI does not change the shape of the CFDs. Large and/or intense convective systems are the same proportion of the population, regardless of the value of the SOI.

A season with increases in the number of convective systems would have a contemporaneous increase in the numbers of large convective systems, including tropical cyclones, according to the shifts observed by Chan (1985). This would result in a change in the mean vertical structure as observed by Berg et al. (2002). Because the study database does not classify by structure, it is not possible to tell directly if the $2 \%$ of convective systems over 10000 $\mathrm{km}^{2}$ are large MCSs or tropical cyclones. From Figure 2, it is possible to suggest that within each sub-region there may be variability in the probability of a particular structure even if the probabilities of its size and intensity classes do not change. In the north region, a strong La Niña would increase the number of large convective systems and perhaps increase the probability that more of them are tropical cyclones rather than MCSs. Additional research is required to investigate this phenomenon.

At regional scales, the interannual stability of the CFDs in Figures 3, 4, 7, and 8 suggests that essentially fixed conditions such as geography and the seasonal cycle largely determine the shape of these spectra. As mentioned earlier, the stability of these spectra is affected by sampling scheme and climate zone. Intraseasonal and interannual modes of variability are important in determining the number of convective systems along the CFD curves. Even in very dry years during dry periods, the reduced regional population of convective systems in the less favorable environment still attains the full spectra of sizes and intensities. Convective systems with a minimum PCT $<135 \mathrm{~K}$ are still approximately $10 \%$ of the population in the driest period of $2001(6 / 15-19)$ as they are in the wettest period in $2003(9 / 14-18)$. It seems intuitive that a region's particular dynamical and thermodynamical environment would set up a range of 
possible convective systems. It remains to be seen why the same entire range occurs despite the phase of the modes of variability, whether intraseasonal or interannual.

The stability of the CFDs and the similarity of results in two very different regions add weight to the claims in previous literature such as Le Barbe' et al. (2002) that numbers, not size and/or intensity of events, determines a wet or dry year or a year with more or fewer large convective systems. It is possible for a small scale study, most likely in a semi-arid or arid region, to conclude otherwise, although it can also be viewed as supporting the idea that during a dry period, we can expect to observe fewer large convective systems and a proportionally larger decrease in precipitation.

\section{Summary}

This study tested the hypothesis that interannual variability in convective activity in tropical continental and oceanic environments is driven by variations in the number of events during the wet season and not by favoring large and/or intense systems. Convective system populations were identified and analyzed from 10 years of TRMM data from West Africa and selected years of TRMM data from the western Pacific tropical cyclone basin.

Convective systems were defined as a cluster of pixels with a PCT below $255 \mathrm{~K}$ and with an area at least $64 \mathrm{~km}^{2}$. The study database consisted of West African convective systems from May to Sep for 1998-2007 and convective systems in the WPTCB from May to Nov for 1998-2007. From the regional databases, CFDs for system minimum PCT and system area were constructed. Hypothesis testing used the non-parametric but powerful Mann-Whitney rank method at $95 \%$ to test whether samples were drawn from the same or different populations.

From the analysis of the regional databases arose the following common points: 
- The CFDs for system minimum PCT exhibited no statistically significant interannual variability.

- The CFDs for system area had two groups of curves, one set of curves 1998-2001 (preboost) and the other set 2002-2007 (post-boost). Within each set, there was no statistically significant interannual variability.

- Anomalously wet periods had about $10 \%$ more convective systems than in average (SOIneutral) years and $20 \%$ more than in anomalously dry periods.

- Anomalies in the number of convective systems resulted in larger anomalies in precipitation.

- Differences in the number of large/and intense systems could be explained by the number of convective systems occurring each year.

The time series analysis performed on the West Africa database produced additional results:

- The amplitude of intraseasonal oscillations displayed interannual variability. Wet years had higher numbers and dry years lower numbers of convective systems during both wet and dry periods.

- The shapes of the CFDs were affected by the seasonal cycle but not by intraseasonal and interannual modes of variability.

- The stability of CFDs was sensitive to the size of the sampling region, sampling period, and climate zone.

The analysis of the regional databases supports the hypothesis of this study and the conclusions of some earlier studies with a more limited scope. Our results also put into context those studies that may have reached a different conclusion based on their sampling methodology 
and study area. Essentially fixed conditions such as geography and the seasonal cycle could explain the stability in the shape of these spectra in both continental and oceanic environments. This leaves intraseasonal and interannual modes of variability responsible for determining the number of convective systems along the CFD curves. Because of the stability of the spectral curves, they could be used as important benchmarks against which populations of convective systems in regional and global model simulations could be compared. Future work should consider why even during dry phases, when it is difficult for any convection to organize, the large and/or intense convective systems still develop, and in the same proportion of the population as in more favorable phases. If models are to create convective system populations matching the observed ranges of sizes and intensities, it is necessary to understand why the regional environment produces these ranges every wet season during each phase of intraseasonal or interannual modes of variability.

\section{Acknowledgments}

We obtained the TRMM data products (1B11 and 3B43) from the NASA-Goddard Distributed Active Archive Center (http://isc.sci.gsfc.nasa.gov/data/datapool/TRMM/). D. Vollaro produced our Pacific map; A. Mekonnen provided wavelet analyses, and H. Ghiradella translated a French-language reference for us. We had useful discussions with R. Carbone, E. Zipser, and the students and post-docs of our West Africa research group: H. Nguyen, A. Mekonnen, S. Hopsch, M. Tanu, S. Nicholls, M. Janiga, G. Berry. We are grateful to C. Liu and two anonymous reviewers for their helpful comments on this manuscript. This work was supported by the NASA Precipitation Measuring Mission grant NNX07AD45G and NSF grants ATM0538164 and ATM0732255. 


\section{References}

Adler, R. F., G. J. Huffman, D. T. Bolvin, S. Curtis, and E. J. Nelson, 2000: Tropical rainfall distributions determined using TRMM combined with other satellite and rain gauge information. J. Appl. Meteor., 39, 2007-2023.

Arguez, A., A. M. Waple, and A. M. Sanchez-Lugo, 2007: State of the climate in 2006. Bull. Amer. Meteor. Soc., 88, S1-S135.

Balme, M., T. Lebel, and A. Amani, 2006: Annees seches et annes humides au Sahel: quo vadimus? Hydrol. Sci. J., 51, 254-271.

Bell, G. D., and Coauthors, 1999: Climate assessment for 1998. Bull. Amer. Meteor. Soc., 80, 1040.

_ 2000: Climate assessment for 1999. Bull. Amer. Meteor. Soc., 81, S1-S50.

Bell, M. A., and P. J. Lamb, 2006: Integration of Weather System Variability to Multidecadal Regional Climate Change: The West African Sudan-Sahel Zone, 1951-98. J. Climate, 19, 53435365.

Berg, W., C. Kummerow, and C. A. Morales, 2002: Differences between East and West Pacific rainfall systems. $J$. Climate, 15, 3659-3672.

Cecil, D. J., S. J. Goodman, D. J. Boccippio, E. J. Zipser, and S. W. Nesbitt, 2005: Three years of TRMM precipitation features. Part I: Radar, radiometric, and lightning characteristics. Mon. Wea. Rev., 133, 543-566.

Chan, J. C. L., 1985: Tropical cyclone activity in the Northwest Pacific in relation to the El Niño/Southern Oscillation phenomenon. Mon. Wea. Rev., 113, 599-606.

Chen, T. C., S. P. Weng, N. Yamazaki, and S. Kiehne, 1998: Interannual variation in the tropical cyclone activity over the western North Pacific. Mon. Wea. Rev., 126, 1080-1090. 
Lamb, P. J., M. A. Bell, and J. D. Finch, 1998: Variability of Sahelian disturbance lines and rainfall during 1951-1987. Water Resources Variability in Africa during the XXth Century, International Association of Hydrologic Sciences, Gentbrugge, Belgium, Publ. 252, 19-26.

Lawrimore, J. H., and Coauthors, 2001: Climate assessment for 2000. Bull. Amer. Meteor. Soc., 82, 1304.

Le Barbe', L., and T. Lebel, 1997: Rainfall climatology of the HAPEX-Sahel region during the years 1950-1990. J. Hydrol., 188-189, 43-73.

Le Barbe', L., T. Lebel, and D. Tapsoba, 2002: Rainfall variability in West Africa during the years 1950-90. J. Climate, 15, 187-202.

Lebel, T., L. L. Barbe', and N. D’Amato, 1997: Rainfall monitoring during HAPEX-Sahel, I, General rainfall conditions and climatology. J. Hydrol., 188-189, 7496.

Levinson, D. H., 2005: State of the climate in 2004. Bull. Amer. Meteor. Soc., 86, S1-S86.

Levinson, D. H., and A. M. Waple, 2004: State of the climate in 2003. Bull. Amer. Meteor. Soc., $85,881$.

Levinson, D. H., and J. H. Lawrimore, 2008: State of the climate in 2007. Bull. Amer. Meteor. Soc., 89, S1-S179.

Mapes, B. E., and R. A. Houze, 1993: Cloud clusters and superclusters over the oceanic warm pool. Mon. Wea. Rev., 121, 1398-1415.

Mathon, V., and H. Laurent, 2001: Life cycle of Sahelian mesoscale convective cloud systems. Quart. J. Roy. Meteor. Soc., 127, 377-406.

McGaughey, G. R., E. J. Zipser, R. W. Spencer, and R. E. Hood, 1996: High resolution passive microwave observations of convective systems over the tropical Pacific Ocean. J. Appl. Meteor., 35, 1921-1947. 
Mohr, K. I., 2004: Interannual, monthly, and regional variability in the wet season diurnal cycle of precipitation in Sub-Saharan Africa. J. Climate, 17, 2441-2453.

Mohr, K. I., and E. J. Zipser, 1996: Mesoscale convective systems defined by their $85 \mathrm{GHz}$ ice scattering signature: Size and intensity comparison over tropical oceans and continents. Mon. Wea. Rev., 124, 2417-2437.

Mohr, K. I., and C. Thorncroft, 2006: The distribution of intense convective systems in West Africa and their relationship to the African easterly jet. Quart. J. Roy. Meteor. Soc., 132, 163176.

Mounier, F., and S. Janicot, 2004: Evidence of two independent modes of convection at intraseasonal timescale in the West African summer monsoon. Geophys. Res. Lett., 31, doi:16110.11029/12004GL020665.

Mounier, F., G. Kiladis, and S. Janicot, 2007: Analysis of the dominant mode of convectively coupled Kelvin waves in the West African monsoon. J. Climate, 20, 1487-1503.

Mounier, F., S. Janicot, and G. N. Kiladis, 2008: The West African monsoon dynamics. Part III: The quasi-biweekly zonal dipole. J. Climate, 21, 1911-1928.

Negri, A. J., T. L. Bell, and L. Xu, 2002: Sampling of the diurnal cycle of precipitation using TRMM. J. Atmos. Oceanic Technol., 19, 1333-1344.

Nesbitt, S. W., E. J. Zipser, and D. J. Cecil, 2000: A census of precipitation features in the Tropics using TRMM: Radar, ice scattering, and lightning observations. J. Climate, 13, 40874106.

Nicholson, S. E., 2000: Land surface processes and Sahel climate. Rev. Geophys., 38, 117-139.

Nicholson, S. E., J. Y. Kim, and J. Hoopingarner, 1988: Atlas of African Rainfall and its Interannual Variability. Florida State University, 237 pp. 
Prabhakara, C., J. R. Iacovazzi, J. A. Weinman, and G. Dalu, 2000: A TRMM microwave radiometer rain rate estimation method with convective and stratiform discrimination. J. Meteor. Soc. Japan, 78, 241-258.

Shein, K. A., 2006: State of the climate in 2005. Bull. Amer. Meteor. Soc., 87, S1-S102.

Spencer, R. W., H. M. Goodman, and R. E. Hood, 1989: Precipitation retrieval over land and ocean with the SSM/I: Identification and characteristics of the scattering signal. J. Atmos. Oceanic Technol., 6, 254-273.

Toracinta, E. R., D. J. Cecil, E. J. Zipser, and S. W. Nesbitt, 2002: Radar, passive microwave, and lightning characteristics of precipitating systems in the Tropics. Mon. Wea. Rev., 130, 802824.

Wang, B., and J. C. L. Chan, 2002: How strong ENSO events affect tropical cyclone activity over the western north Pacific. J. Climate, 15, 1643-1658.

Waple, A. M., and J. H. Lawrimore, 2003: State of the climate in 2002. Bull. Amer. Meteor. Soc., 84, 800 .

Zolman, J. L., E. J. Zipser, and K. I. Mohr, 2000: A comparison of tropical mesoscale convective systems in El Nino and La Nina. J. Climate, 13, 3314-3326. 


\section{List of Figures}

Figure 1. The study area in West Africa. The large box defines the region in which convective systems were identified and analyzed, approximately $18 \mathrm{~W}-30 \mathrm{E}, 4-20 \mathrm{~N}$.

Figure 2. The Western Pacific tropical cyclone basin and three sub-regions. Shading denotes mean SST for May through November, light shading for regions $300-302 \mathrm{~K}$ and darker shading above $302 \mathrm{~K}$. Storm symbols denote the formation locations of tropical cyclones between May and November in a) 1998 La Niña event, b) 1999 La Niña event, c) 2002 El Niño event.

Figure 3. a) CFDs for total convective system area in $\mathrm{km}^{2}$ for each year in the TRMM era for West Africa. The blue-to-red gradient color scheme represents pre-boost years in blues with closed symbols and post-boost years in reds with open symbols. b) High-low chart depicting the spread among the CFDs 1998-2007 for large convective systems. The square denotes the median value in each area bin.

Figure 4. CFDs for a) system minimum PCT (K) and b) mean PCT (K) of mature convective cells of convective systems with a minimum of 4 cells in the mature lifecycle stage. Series markers are consistent with Figure 3a.

Figure 5. Time series of the 5-day running mean of daily total convective systems for all of West Africa for the wet seasons of 1998 (near normal precipitation, dotted black line), 2001 (drier than normal, solid gray line), 2003 (wetter than normal, dashed black line).

Figure 6. CFDs for system minimum PCT for wet and dry periods of a) 2001 and b) 2003. The wet and dry periods are 4 days centered on the peaks and troughs of Figure 5. There is a gap in August 2001 due to missing data during the boosting of the TRMM satellite. Red lines with open symbols denote dry periods. Blue lines with closed symbols denote wet periods. The thick gray line is the seasonal mean CFD. 
Figure 7. East region CFDs for a) system minimum PCT in $\mathrm{K}$ and b) total system area in $\mathrm{km}^{2}$. c) The difference in the area CFDs for 2000 vs. 2005. Series markers are consistent with Figure 3a. Figure 8. CFDs for system minimum PCT in K (left column) and total system area (right column) in $\mathrm{km}^{2}$ for the ENSO events in a) and b) west region $\mathrm{W}, \mathrm{c}$ ) and d) east region $\mathrm{E}, \mathrm{e}$ ) and f) north region N. La Niña years are in blue, El Niño in red, neutral in gray.

Figure 9. CFDs for system minimum PCT for a $4^{\circ} \times 4^{\circ}$ box centered on a) southern Niger and b) the Ivory Coast and Ghana. Each year of the TRMM era is represented. "N" (green, hashed markers) refers to wet seasons in which regional total precipitation was near-normal, "D" (red, open markers) to below normal, and "W" (blue, closed markers) to above normal. The thick gray line is the regional mean for 1998 , a near-normal wet season. 


\section{List of Tables}

Table 1 . Convective system densities for $1998-2007$, normalized by a fixed area, a $1^{\circ} \times 1^{\circ}$ box on the equator.

Table 2. Percent change in the number of convective systems in the WPTCB during the ENSO events vs. the neutral season, 2005. Percentages were calculated from regional counts used to calculate the entries in Table 1.

Table 3. Percent change in the daily total precipitation per 3B43 gridcell for 1999 and 2002 . For the WPTCB, the comparison is to SOI-neutral 2005 for May-Nov. For West Africa, the comparison is to near-normal 1998 for May-Sep. 


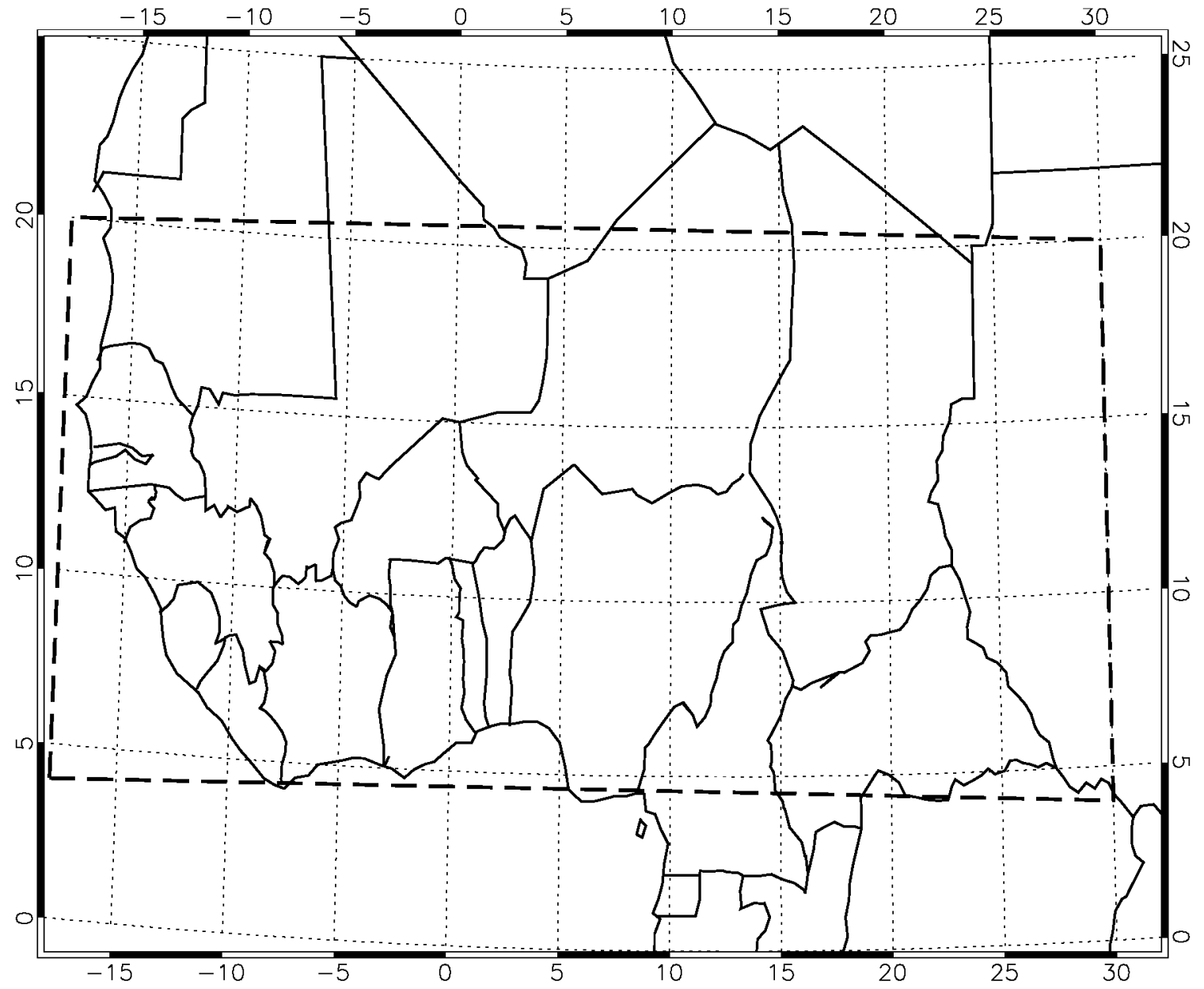

Figure 1. The study area in West Africa. The large box defines the region in which convective systems were identified and analyzed, approximately $18 \mathrm{~W}-30 \mathrm{E}, 4-20 \mathrm{~N}$. 

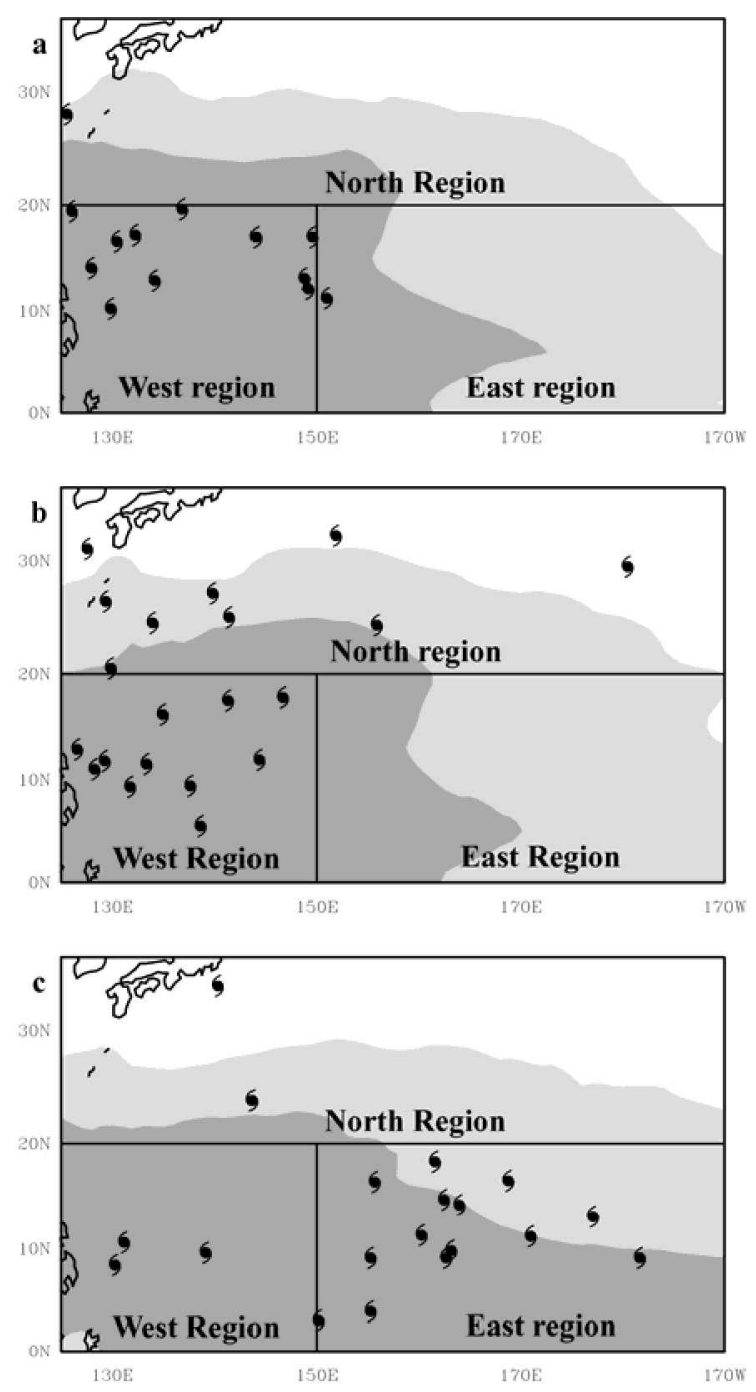

Figure 2. The Western Pacific tropical cyclone basin and three sub-regions. Shading denotes mean SST for May through November, light shading for regions 300-302 K and darker shading above $302 \mathrm{~K}$. Storm symbols denote the formation locations of tropical cyclones between May and November in a) 1998 La Niña event, b) 1999 La Niña event, c) 2002 El Niño event. 

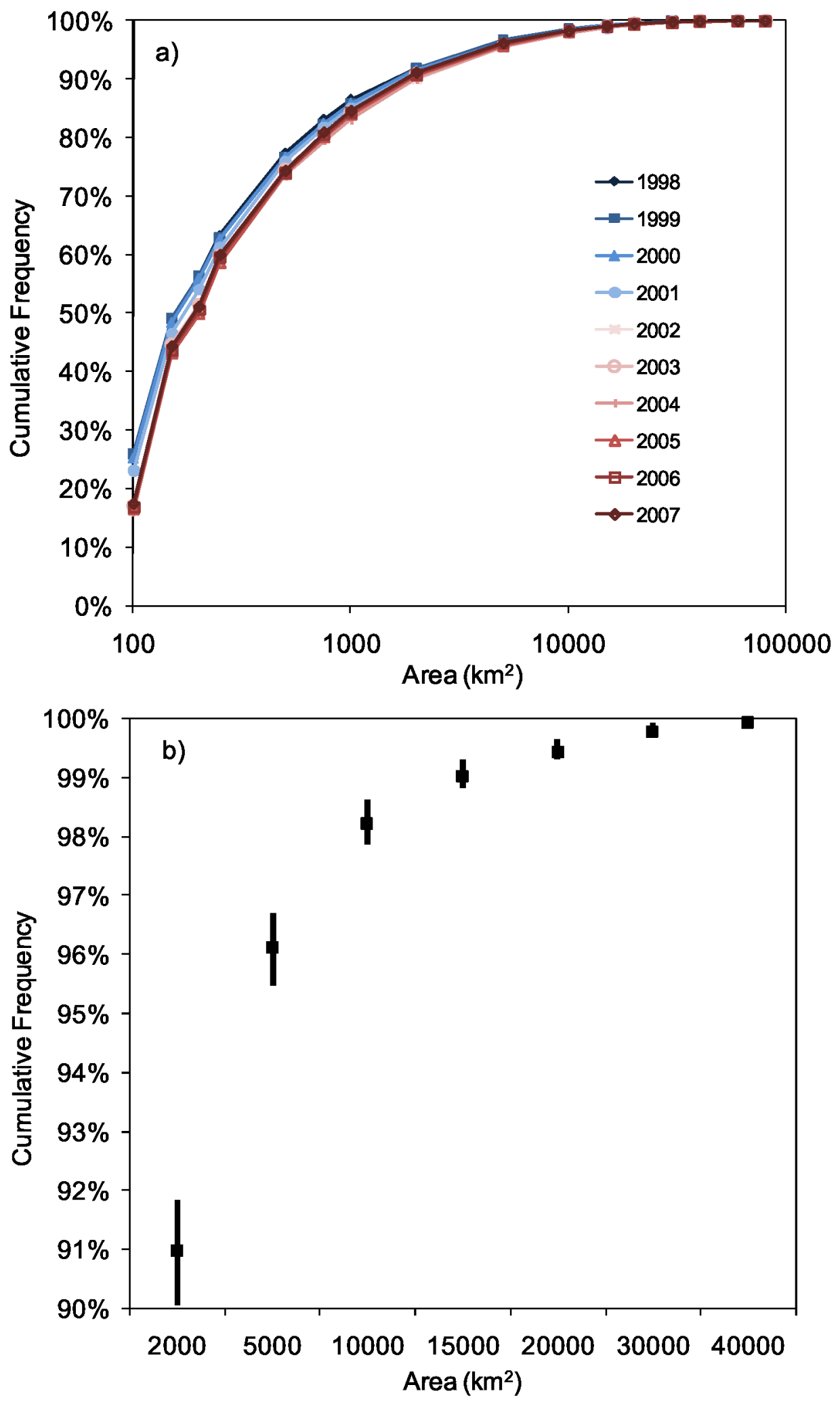

Figure 3. a) CFDs for total convective system area in $\mathrm{km}^{2}$ for each year in the TRMM era for West Africa. The blue-to-red gradient color scheme represents pre-boost years in blues with closed symbols and post-boost years in reds with open symbols. b) High-low chart depicting the spread among the CFDs 1998-2007 for large convective systems. The square denotes the median value in each area bin. 

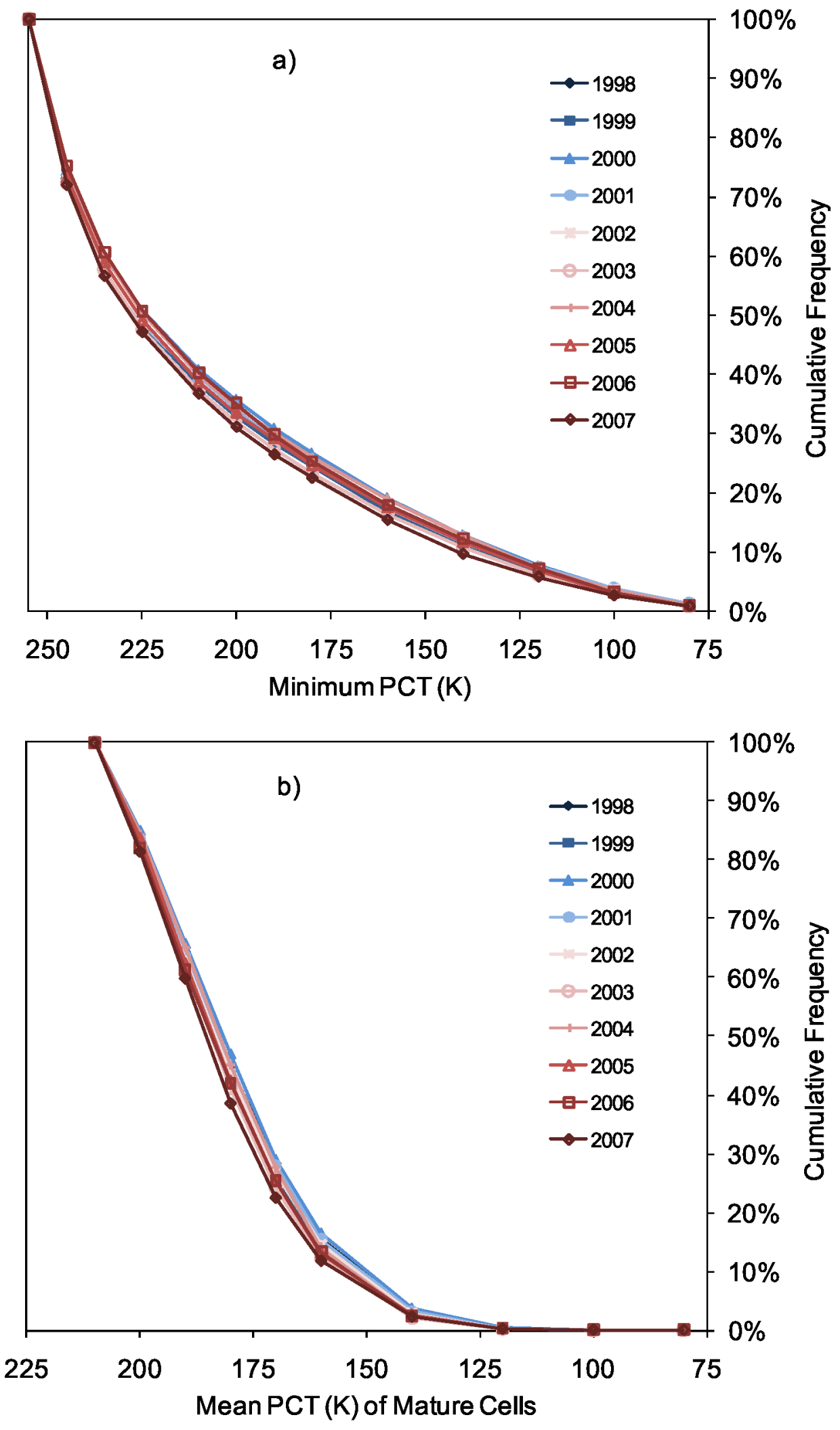

Figure 4. CFDs for a) system minimum PCT (K) and b) mean PCT (K) of mature convective cells of convective systems with a minimum of 4 cells in the mature lifecycle stage. Series markers are consistent with Figure 3a. 


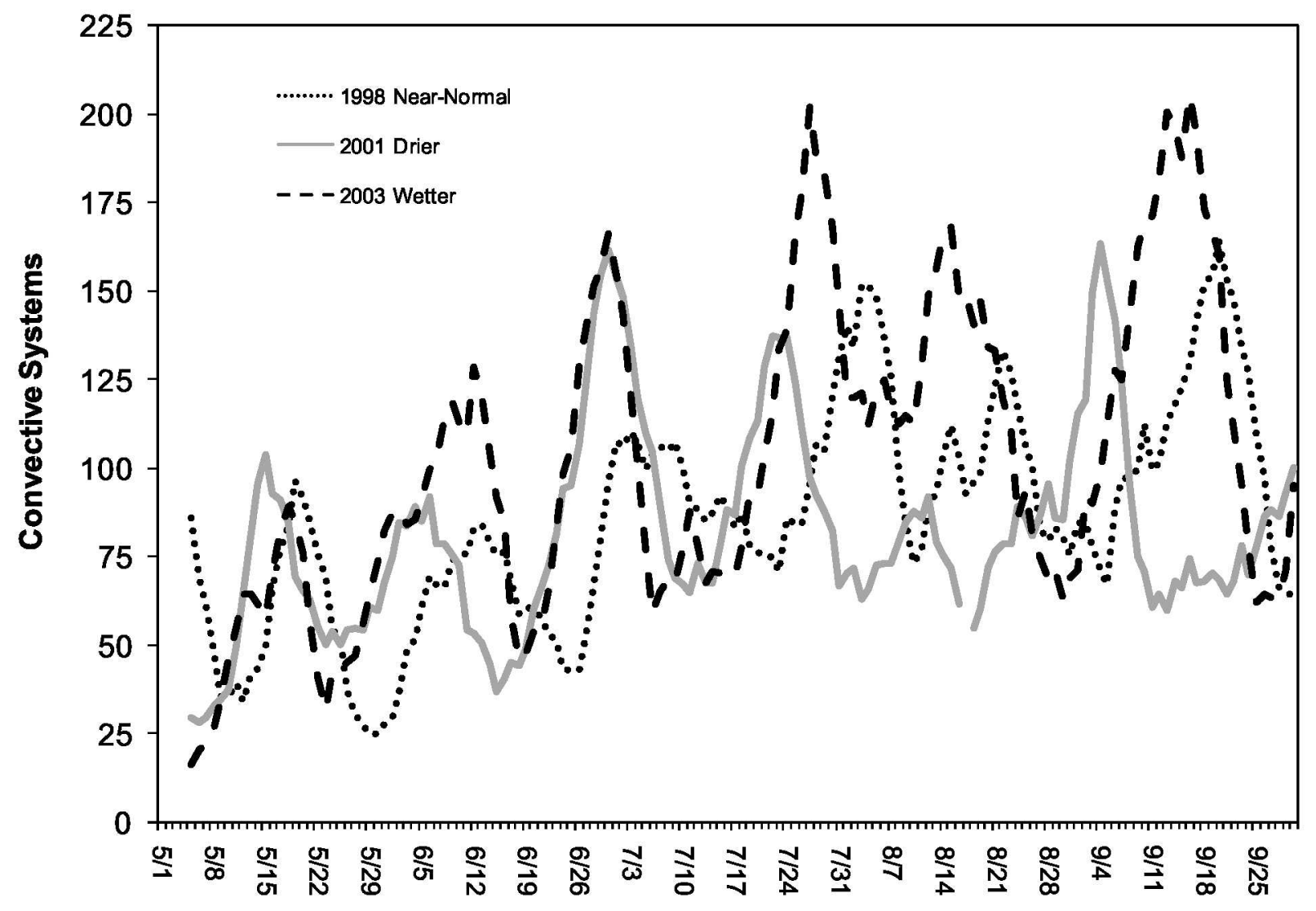

Figure 5. Time series of the 5-day running mean of daily total convective systems for all of West Africa for the wet seasons of 1998 (near normal precipitation, dotted black line), 2001 (drier than normal, solid gray line), 2003 (wetter than normal, dashed black line). 

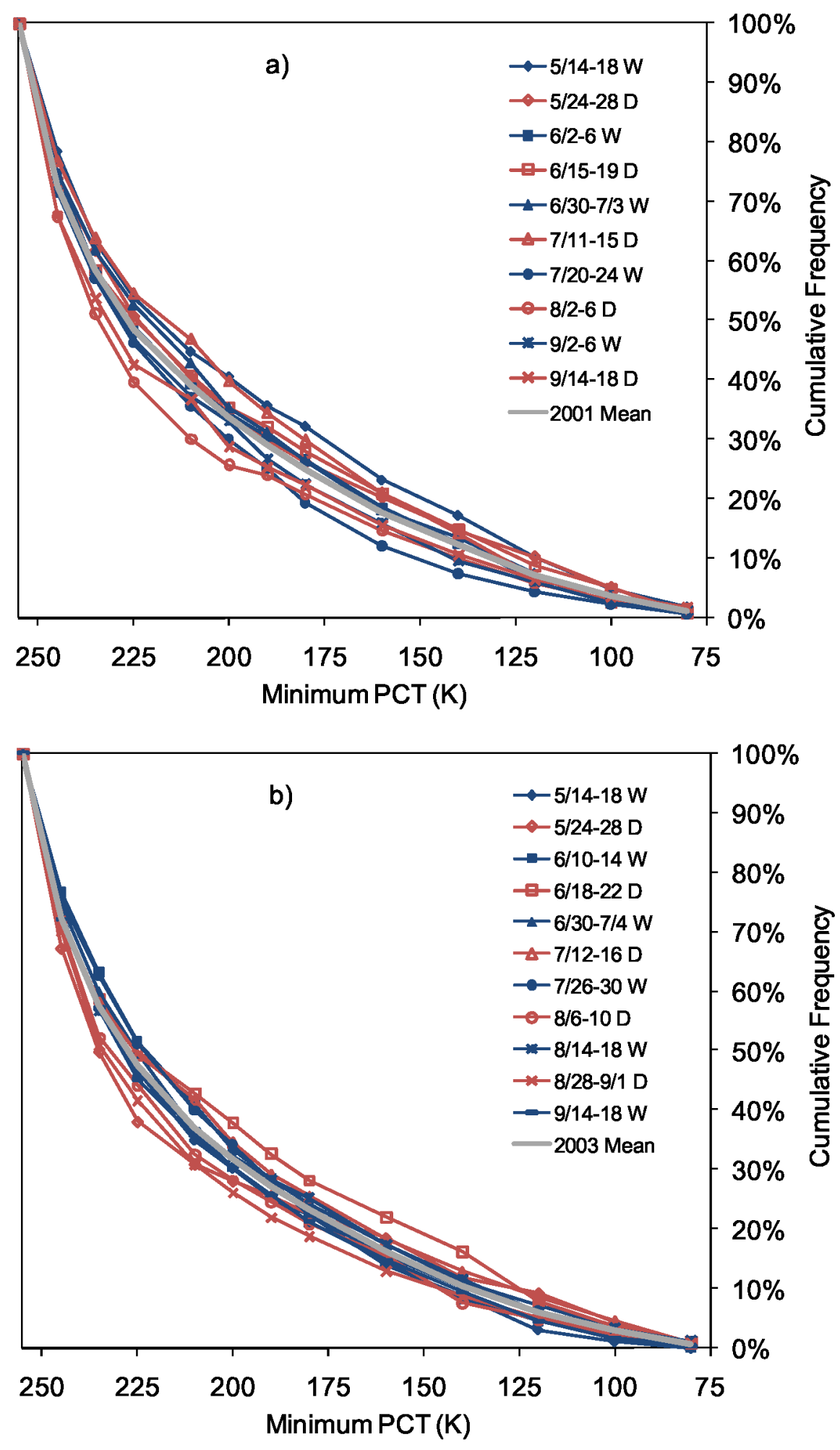

Figure 6. CFDs for system minimum PCT for wet and dry periods of a) 2001 and b) 2003. The wet and dry periods are 4 days centered on the peaks and troughs of Figure 5 . There is a gap in August 2001 due to missing data during the boosting of the TRMM satellite. Red lines with open symbols denote dry periods. Blue lines with closed symbols denote wet periods. The thick gray line is the seasonal mean CFD. 

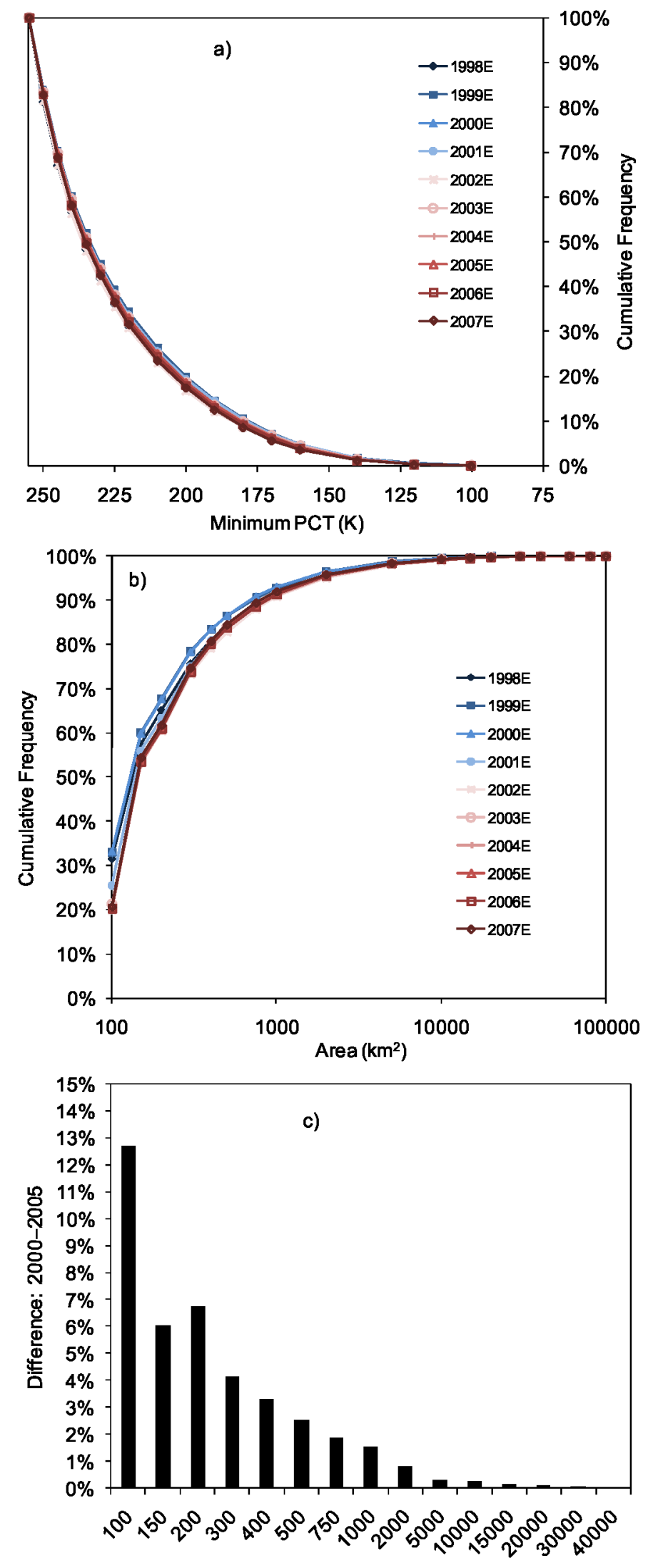

Area $\left(\mathrm{km}^{2}\right)$

Figure 7. East region CFDs for a) system minimum PCT in $\mathrm{K}$ and b) total system area in $\mathrm{km}^{2}$. c) The difference in the area CFDs for 2000 vs. 2005. Series markers are consistent with Figure 3a. 

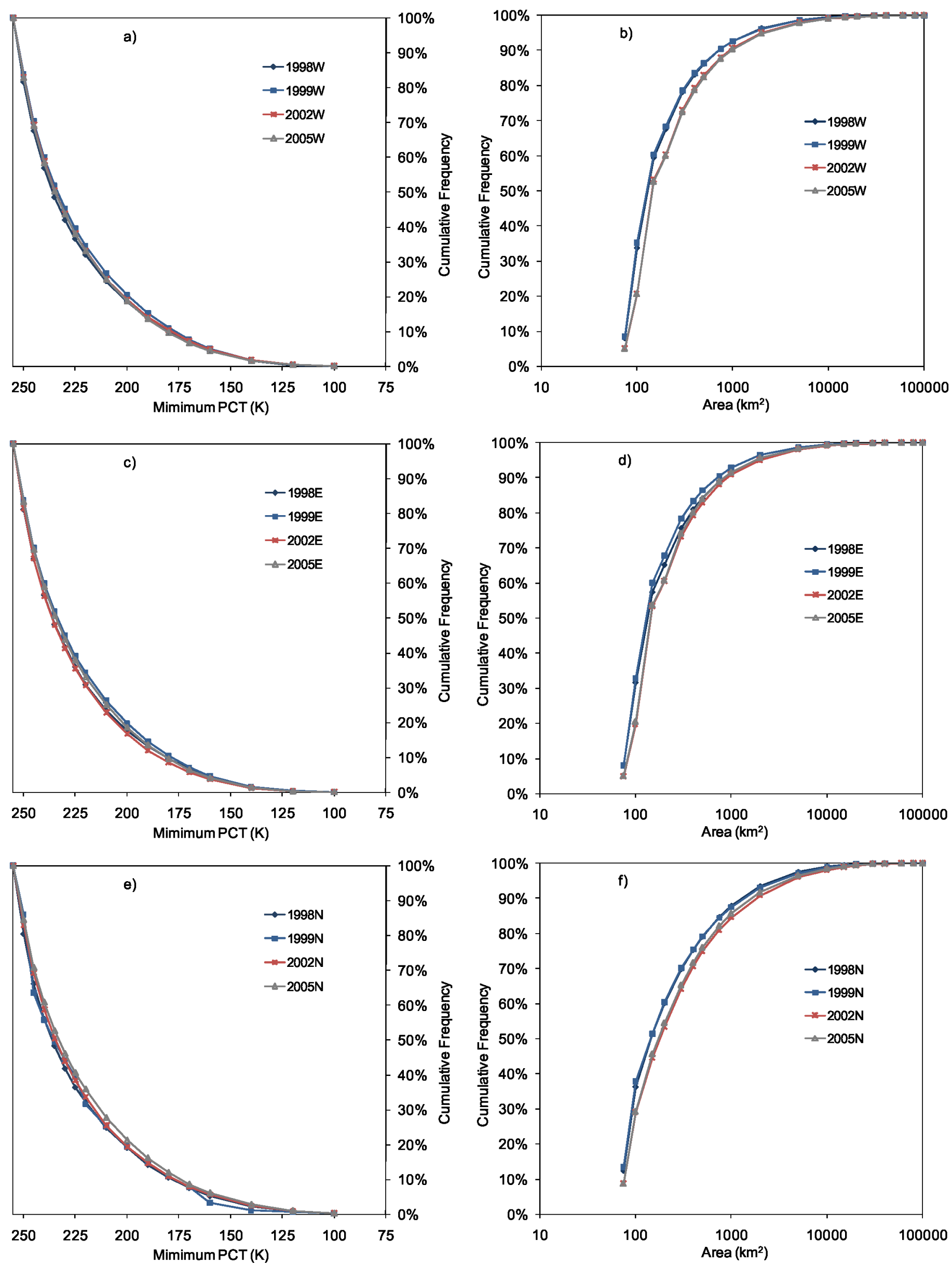

Figure 8. CFDs for system minimum PCT in K (left column) and total system area (right column) inzkikm ${ }^{2}$ for the ENSO events in $a$ ) and b) west region $W, c$ ) and d) east region $E, e$ ) and f) north region $N$. La Niña years are in blue, El Niño in red, neutral in gray. 

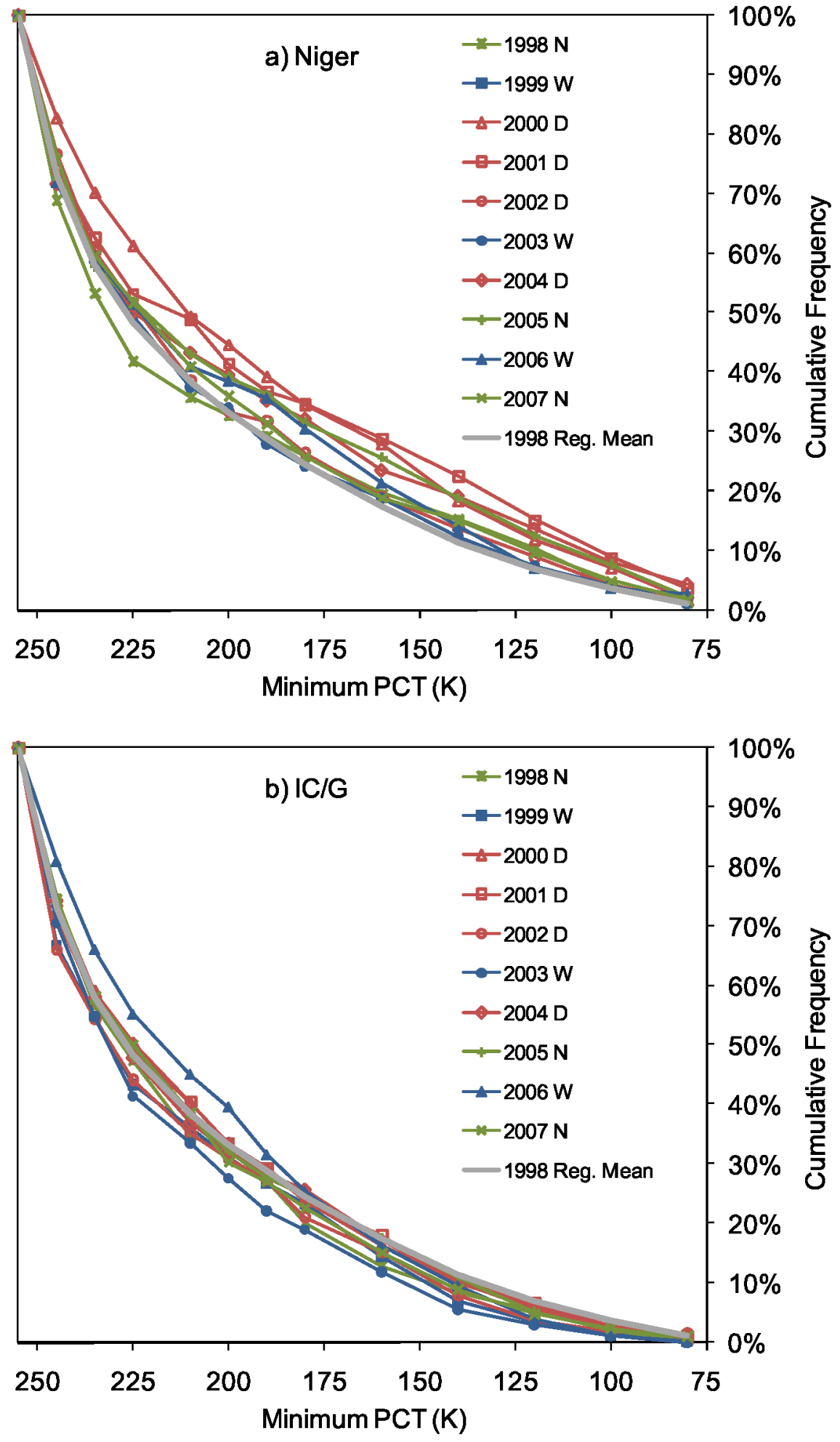

Figure 9. CFDs for system minimum PCT for a $4^{\circ} \times 4^{\circ}$ box centered on a) southern Niger and b) the Ivory Coast and Ghana. Each year of the TRMM era is represented. "N" (green, hashed markers) refers to wet seasons in which regional total precipitation was near-normal, "D" (red, open markers) to below normal, and "W" (blue, closed markers) to above normal. The thick gray line is the regional mean for 1998, a near-normal wet season. 


\begin{tabular}{|c|c|c|c|c|}
\hline \multicolumn{2}{|c|}{ West Africa } & \multicolumn{3}{|c|}{ WPTCB } \\
\hline Year & $\begin{array}{c}\text { Convective } \\
\text { Systems } \\
\text { per box }\end{array}$ & $\begin{array}{c}\text { Convective } \\
\text { Systems } \\
\text { per box } \\
\text { West }\end{array}$ & North & East \\
\hline 1998 & 18 & 60 & 27 & 29 \\
\hline 1999 & 20 & 77 & 29 & 43 \\
\hline 2000 & 17 & 75 & 25 & 44 \\
\hline 2001 & 16 & 66 & 28 & 52 \\
\hline 2002 & 17 & 57 & 21 & 55 \\
\hline 2003 & 21 & 70 & 26 & 55 \\
\hline 2004 & 17 & 62 & 25 & 60 \\
\hline 2005 & 19 & 71 & 27 & 52 \\
\hline 2006 & 20 & 60 & 24 & 52 \\
\hline 2007 & 19 & 76 & 28 & 48 \\
\hline Boxes & 751 & 492 & 918 & 788 \\
\hline
\end{tabular}

Table 1 . Convective system densities for $1998-2007$, normalized by a fixed area, a $1^{\circ} \times 1^{\circ}$ box on the equator. 


\begin{tabular}{c|ccc}
\hline Year & West & North & East \\
\hline 1998 La Niña & $-16 \%$ & $-1 \%$ & $-44 \%$ \\
1999 La Niña & $7 \%$ & $9 \%$ & $-17 \%$ \\
2002 El Niño & $-20 \%$ & $-22 \%$ & $6 \%$ \\
\hline
\end{tabular}

Table 2. Percent change in the number of convective systems in the WPTCB during the ENSO events vs. the neutral season, 2005. Percentages were calculated from regional counts used to calculate the entries in Table 1. 


\begin{tabular}{c|rrrr}
\hline Year & West & North & East & West Africa \\
\hline 1999 & $17 \%$ & $19 \%$ & $-29 \%$ & $19 \%$ \\
2002 & $-29 \%$ & $-32 \%$ & $14 \%$ & $-13 \%$ \\
$\begin{array}{c}\text { Neutral Year } \\
\left(\mathrm{mm} \mathrm{d}^{-1} \text { gridcell }\right.\end{array}$ & 7.0 & 3.6 & 5.1 & 4.2 \\
$\begin{array}{c}\text { Gridcells } \\
\left(0.25^{\circ} \times 0.25^{\circ}\right)\end{array}$ & 8000 & 13420 & 12880 & 12545 \\
\hline
\end{tabular}

Table 3. Percent change in the daily total precipitation per 3B43 gridcell for 1999 and 2002 . For the WPTCB, the comparison is to SOI-neutral 2005 for May-Nov. For West Africa, the comparison is to near-normal 1998 for May-Sep. 


\section{The interannual stability of cumulative frequency distributions for convective system size}

and intensity

Karen I. Mohr (GSFC, Code 613.1)

John Molinari (University at Albany, SUNY)

Chris D. Thorncroft (University at Albany, SUNY)

Citation: Mohr, K. I., J. Molinari, and C. D. Thorncroft, 2009: The interannual stability of cumulative frequency distributions for convective system size and intensity. J. Climate, 19, 5218-5231.

We analyzed the characteristics of convective system populations in West Africa and the western Pacific tropical cyclone basin. We asked whether a wetter than average year is driven by an increase in the number of events during the wet season or by favoring large and/or intense convective systems. This question has been answered differently in previous work, although this the first study to ask the question for two very different tropical regions. We used TRMM TMI data at $85 \mathrm{GHz}$ to identify and classify convective systems in West Africa from May-Sep 1998-2007 and in the western Pacific from May-Nov 1998-2007. We constructed annual cumulative frequency distributions for system minimum brightness temperature (a proxy for system intensity) and system area. For both regions, there were no statistically significant differences among the annual curves for system minimum brightness temperature. There were two groups of system area curves, split by the TRMM altitude boost in 2001. Within each set, there was no statistically significant interannual variability. Sub-setting the database revealed some sensitivity in distribution shape to the size of the sampling area, length of sample period, and climate zone. Comparing our results to previous work revealed that these sensitivities were responsible for differing conclusions. From our regional perspective, the probability that a convective system will attain a particular size or intensity does not change interannually. Variability in the number of convective events appeared to be more important in determining whether a year is wetter or drier than normal. 